UNIVERSITY OF THE

INCARNATE WORD.

FEIK SCHOOL of PHARMACY

\section{Synthesis of an intermediate towards the total synthesis of the potential cytotoxic agent Callyspongamide A}

Ruiz, E. M.' ${ }^{1}$, Salazar, A. ${ }^{1}$, Lopez, J.1, Dankert, K. ${ }^{2}$, Rocha, S. ${ }^{2}$, Carvalho, P. ${ }^{2}$

School of Mathematics, Science, and Engineering, University of the Incarnate Word, San Antonio, TX

${ }^{2}$ Feik School of Pharmacy, University of the Incarnate Word, San Antonio, TX

\title{
PURPOSE
}

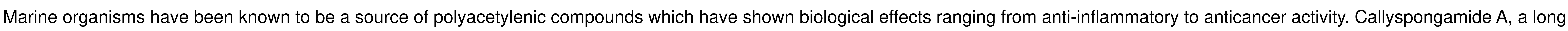

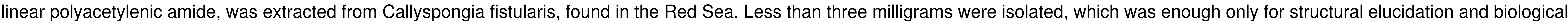

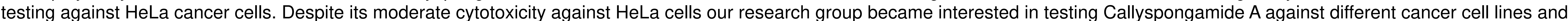
search for other possible biological activities of this unusual polyacetylenic amide.

\section{RATIONALE AND SIGNIFICANCE}

Extraction of significant quantities of Callyspongamide $A$ from sponges is not practical, which makes the total synthesis of this natural compound the best alternative. Undergraduate student's involvement offers laboratory experience and opportunities for discussion of theoretical concepts learned in class.

\section{METHODS}

Retrosynthetic analysis (Scheme 1) of Callyspongamide A (1) calls for the protection of a haloalkyl alcohol and an acetylenic alcohol with different protecting groups, coupling both through lithium-mediated alkylation. Removal of THP with subsequent oxidation to carboxylic acid and coupling to phenethylamine finishes one "half" of the molecule. Deprotection and controlled oxidation of the second alcohol to an aldehyde, followed by Stork-Zhao olefination and acetylene alkylation is expected to yield Callyspongamide $A$.

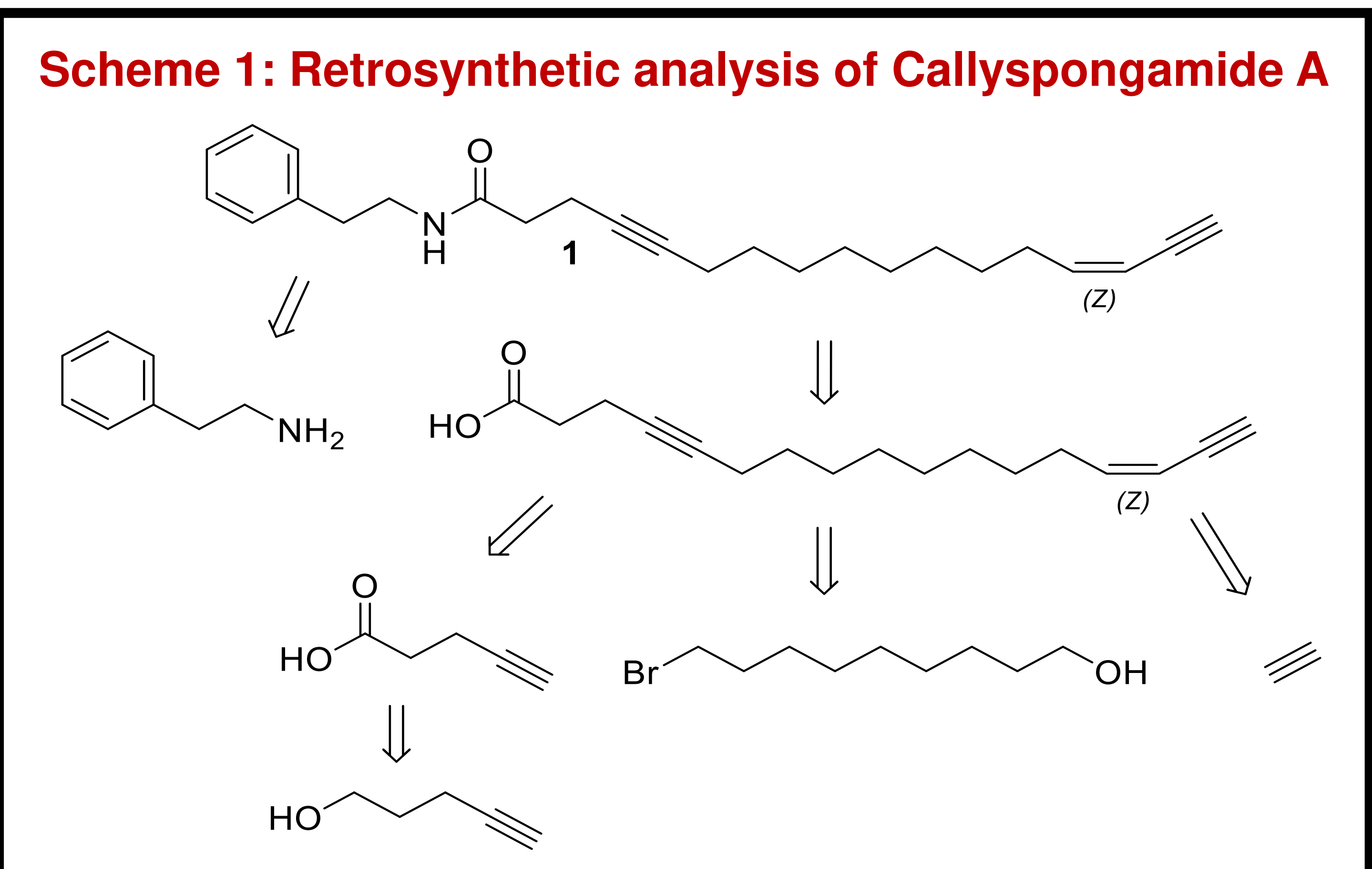

$$
\text { Scheme 2: Protection of 4-propyn-1-ol }
$$$$
\begin{gathered}
\text { Scheme } 3 \\
\text { Protection of 9-bromo-1-nonanol }
\end{gathered}
$$$$
\sim \mathrm{OH}
$$$$
\text { DIPEA } \mid \mathrm{Cl} \widehat{\mathrm{O}}^{\sim 0} \mathrm{O}
$$

$\mathrm{NO}_{\mathrm{O}} \mathrm{\gamma}_{\mathrm{O}}$

Scheme 4: Preparation of 14-((2-methoxyethoxy)methoxy)tetradec-4-yn-1-ol

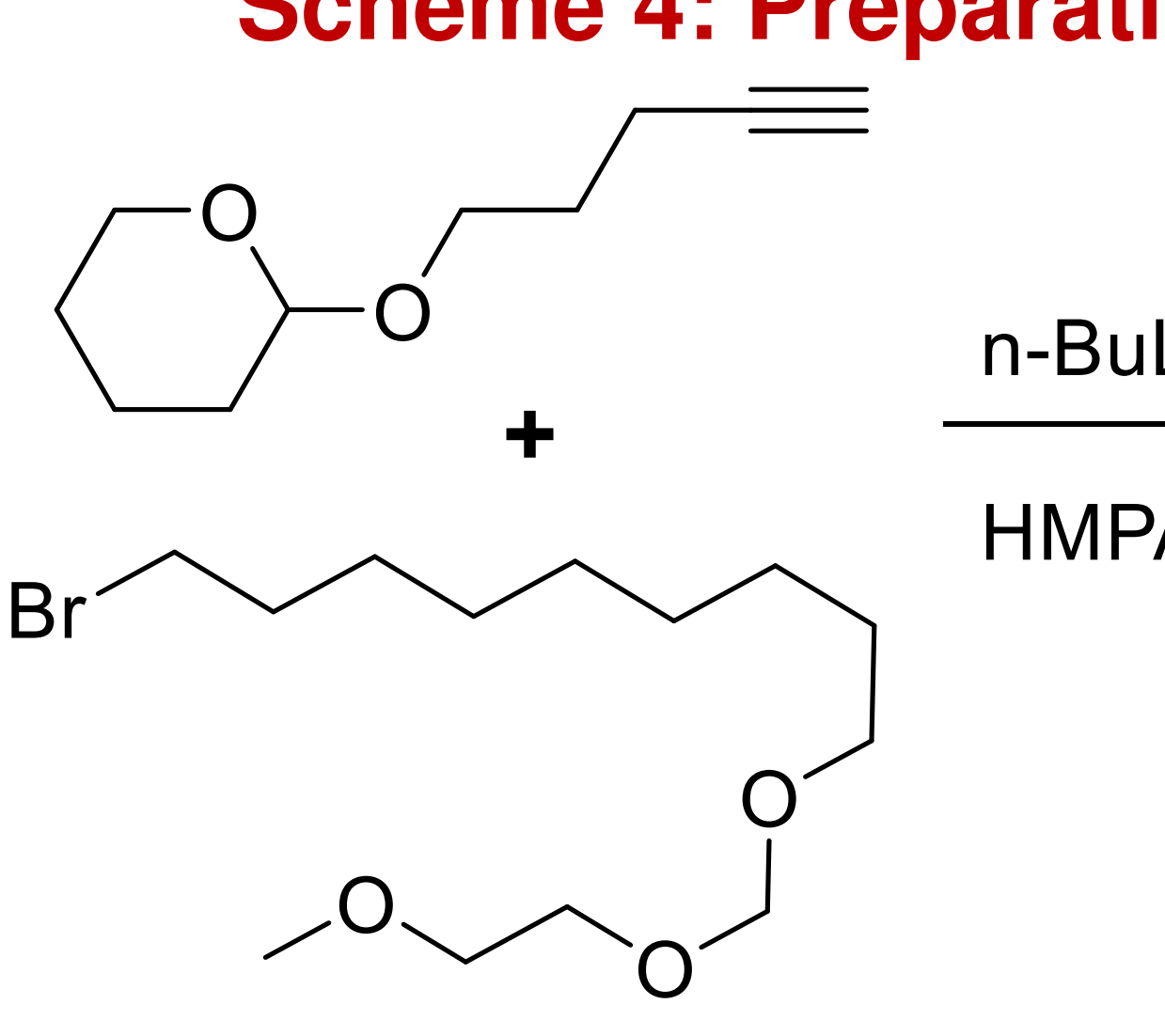

$$
\underset{\text { HMPA }}{\mathrm{n} \text {-BuLi }}
$$

$$
\text { Montmorillonite K10 }
$$

\section{RESULTS}

4-propyn-1-ol was protected with dihydropyran forming 2 (Scheme 2), and 9-bromo-1-nonanol was protected with methoxy ethoxymethyl chloride forming 3 (Scheme 3). The two where coupled forming 4, which was submitted to mildly acidic conditions to remove the THP protecting group. The resulting monoprotected alkynol 14-((2-methoxyethoxy)methoxy)tetradec-4-yn-1-ol 5 was characterized through NMR spectrometry. Next steps involve the planned final synthetic reactions and establishment of the synthetic methodology for the preparation of analogs to explore structure-activity relationship.

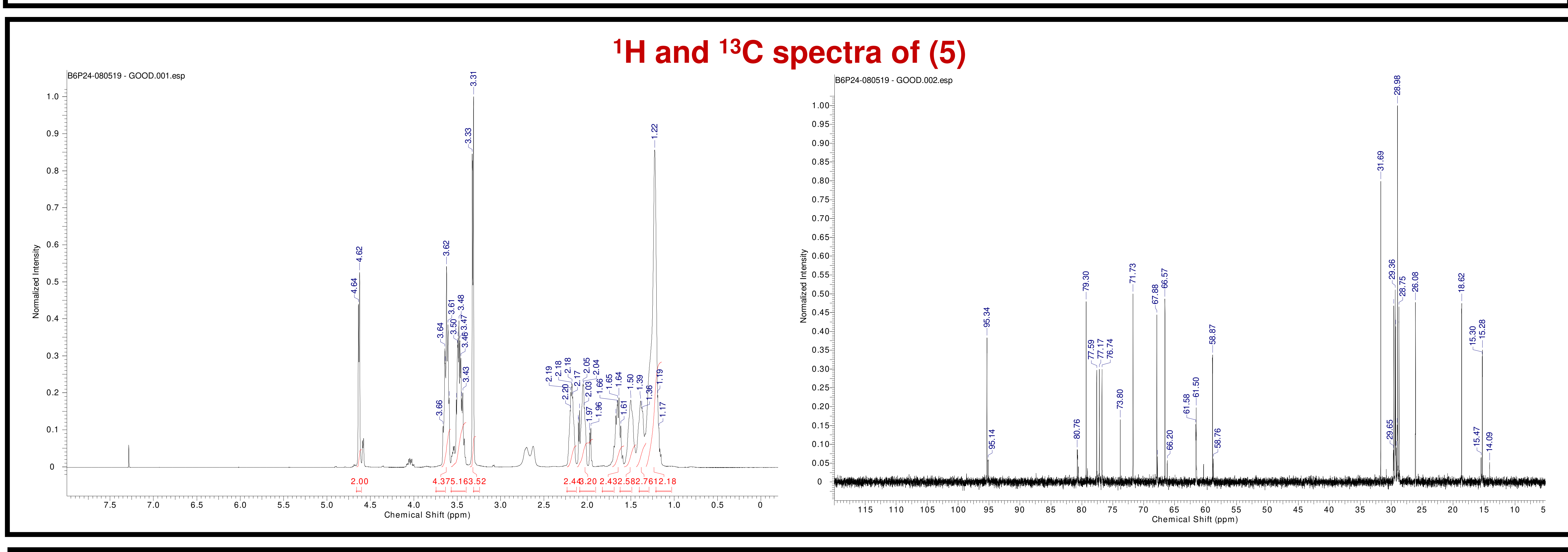

CONCLUSIONS

Student driven research can be a slow process as it often is delayed by academic commitments such as assignments, exam preparation, service activities. It is a valuable tool in giving students the opportunity to put in practice theoretical concepts learned in class and opens opportunities for presentations at conferences which enrich their preparation for the job market. The present student-driven project reached about halfway into the proposed synthetic strategy and it is expected to conclude within the next year.

\section{Acknowledgments}

Biomedical Research Grant - Beta and Melvin Leazar Memorial Fund of the SA Area Foundation University of the Incarnate Word - Feik School of Pharmacy intramural research grant

School of Mathematics, Science, and Engineering of the University of the Incarnate Word -

Honors Program of the University of the Incarnate Word 